\title{
Secondary Cerebral Hodgkin Lymphoma
}

National Cancer Institute

\section{Source}

National Cancer Institute. Secondary Cerebral Hodgkin Lymphoma. NCI Thesaurus. Code C5057.

A Hodgkin lymphoma that has spread to the cerebral hemisphere following the initial presentation in another nodal or extranodal site. 